\title{
Evaluating Antimicrobial activity of Aloe vera Plant Extract in Human Life
}

\author{
Saket Kumar ${ }^{1 *}$, Dan Singh Jakhar ${ }^{2}$ and Rajesh Singh ${ }^{2}$ \\ ${ }^{1}$ Institute of Environment and Sustainable development, BHU, India \\ ${ }^{2}$ Dept. of Genetics and Plant Breeding, BHU, India
}

Received: November 26, 2017; Published: December 05, 2017

*Corresponding author: Saket Kumar, Institute of Environment and Sustainable development, BHU, Varanasi, India; Email: saketjntradelink@gmail.com

\begin{abstract}
Aloe vera is a perennial draught resistant plant containing more amount of gel in fluctuating amount to different season. Aloe plant is containing a variety of mineral elements and calcium, iron, and zinc. Aloe gel also contains polysaccharides, proteins, lipids, sugars, minerals, phenolic compounds, glucomannan and acemannan. Its composition accelerates wound healing, activating macrophages, stimulating immune system as well antibacterial and antiviral effects. Acemannan is effect as indirect anti-microbial activity through its ability and stimulate phagocytic leukocytes. Such types, it has more antimicrobial value like medicines. The aim of this study are evaluating antimicrobial activity of aloe vera gel such as antibacterial, antifungal, and antiviral activity to which solve human problems in life.
\end{abstract}

Keywords: Aloe Plant; Gel, Antibacterial Activity; Antifungal Activity; Antiviral Activity

\section{Introduction}

Aloe vera (A. barbadensis Miller L.) is most biologically active among 400 species [1-4]. The genus Aloe belonging to family Alliaceae is a succulent plant of $80-100 \mathrm{~cm}$ in height which matures in 4-6 years and survives for nearly 50 years under favorable conditions. The plant is native to southern and eastern Africa along the upper Nile in the Sudan, and it was subsequently introduced into northern Africa and naturalized in the Mediterranean region and other countries across the globe. Aloe is commercially cultivated in Aruba, Bonaire, Haiti, India, South Africa, the United States of America, and Venezuela [1] while the finest quality of Aloe is grown in desert of Southern California. According to World Health Organization (WHO), aloe is the best source for obtaining a variety of drugs [2], because this plant can survive in both hot and cold temperatures. Plant extracts represent a continuous effort to find new compound against pathogens. Approximately $20 \%$ of the plants found in the world have been submitted to biological test, and a substantial number of new antibiotics introduced on the market are obtained from natural or semi synthetic resources [3]. Aleo gel is bactericidal against (bacteriostatic) for common wound infecting bacteria (in vitro). The aloin A and B (barbaloin) are 1,8-dihydroxyanthracene glycosides [4], after oral administration these are not absorbed in the upper intestine, and hydrolyzed in the colon by intestinal bacteria. It has following antimicrobial activities which generally observed after oral administration in 6-24 hours.
Anti-microbial Properties: The anti-microbial activity of aloe juice was investigated by agar disc diffusion against bacteria, fungi and yeast [5]. Aloe juice showed anti-bacterial activity against the Gram -ve bacteria (Pseudomonas aeruginosa, Klebsiella pneumonniae, E.coli and Salmonella typhimurium) and Candida albicans (in vitro) A. hydrophilia and E. coli and not against any fungi or yeast tested. Similar results have been obtained for anti-microbial activity of the aloe juice against Gram + ve bacteria by Alemdar and Agaoglu [6] (Mycobacterium smegmatis, Staphylococcus aureus, Enterococcus faecalis, Micrococcus luteus and Bacillus sphericus). Heggers et al. [7] tested Aloe vera gel against ten bacterial strains (Staphylococcus aureus, Streptococcus pyogenes, Streptococcus agalactiae, Escherichia coli, Serratia marcescens, Klebsiella sp., Enterobacter sp., Citrobacter sp., Bacillus subtilis and Candida albicans), at $90 \%$ concentration aloe gel that was effective against all the organisms but at the $70 \%$ concentration only against S. pyogenes. [8] tested preserved aloe gel extract and an unpreserved aloe extract against Pseudomonas aeruginosa, Enterobacter aerogenes, Staphylococcus aureus and Klebsiella pneumoniae. It was found that preserved Aloe gel extract was more effective in controlling bacterial growth. Aloe vera gel was shown to inhibit the growth of gram positive bacteria, Shigella flexneri and Streptococcus pyogenes [9].

Antibacterial Activity: Aloe vera gel is a bactericidal agent causing against Pseudomonas aeruginosa and acemannan and 
prevent human lung epithelial cells from adhering in a monolayer culture [10]. Using a rat model, suggested that the antibacterial effect of the Aloe vera gel (in vivo) could enhance the wound healing process by eliminating the bacteria that contributed to inflammation [7]. The aloe extract was potent against three strains of Mycobacterium (M. fortuitum, M. smegmatis and M. kansasi) and a strong antimycobacterial activity against M. tuberculosis as well as antibacterial activity against $P$. aeruginosa, E. coli, $S$. aureus and $S$. typhi. Thus, Aloe secundiflora could be a rich source of antimicrobial agents [11]. Aloe vera was shown to inhibit microbes like Staphylococcus aureus [12], Candida albicans [13] Pseudomonas aeruginosa [14], and Klebsiella pneumoniae. It has indirect antimicrobial property through self ability to stimulate phagocytic leukocytes [15].

Antiviral Activity: Aloe gels are effective antiviral agent in several ingredients, such as acemannan reduced herpes simplex infection in two cultured target cell lines. Lectins fractions of aloe gel directly inhibited the cytomegalovirus proliferation in cell culture, perhaps by interfering with protein synthesis [16]. A purified sample of aloe emodin was effective against infectivity of herpes simplex virus Type I and Type II and it was capable of inactivating all of the viruses, including varicella zoster virus, influenza virus, and pseudo rabies virus [17]. In some cases anthroquinones are treated herpes simplex virus under electron micrograph examination. Such types result is indicated that anthraquinone extract from aloe plant variety directly enveloped viruses. These fluctuations are indirectly effected due to stimulation of the immune system. The anthraquinone aloin also inactivates various enveloped viruses such as herpes simplex, varicella zoster and influenza [18].

Antifungal Activity: Aloe gel is evaluated on the mycelium development of Rhizoctonia solani, Fusarium oxysporum and Colletotrichum coccodes that showed an inhibitory effect of the pulp of aloevera on F. oxysporum at $10^{4} \mu \mathrm{L}$-1. The liquid fraction is reduced rate of colony growth at a concentration of $10^{5} \mu \mathrm{L}$ L- 1 in $R$. solani, $F$. oxysporum and $C$. coccodes [19]. A fresh leaf extract of $A$. barbadensis and $A$. arborescens have anti-fungal potential against Aspergillus niger, Cladosporium herbarum and Fusarium moniliforme and inhibit the growth of fungi [20]. Aloe juices are anti-inflammatory, anti-arthritic activity, antibacterial and hypoglycaemic effects [12] for bacteria inhibit growth of Streptococcus and Shigella species in vitro. Agarry et al., [12] showed that aloe gel inhibited the growth of Trichophyton mentagrophytes $(20.0 \mathrm{~mm})$, while the leaf possesses inhibitory effects in Pseudomonas aeruginosa and Candida albicans. Another aloe constituents are includes saponins. These are soapy substances of gel that capable of cleaning and perform strongly antimicrobial against for bacteria, viruses, fungi and yeasts [21].

\section{Conclusion}

Aloe plant have important role in antimicrobial activity in everyday life. Aloe gel is mostly use in humanity for cosmetic, burn and medicinal application. Aloe plant has major role in the promotion of recombinant-DNA based product, targeting compounds of value to be isolated and produced in stable and realistic quantities. Such type aloe is a "wonder plant" because it use in multiple problems like antiseptic, anti-inflammatory agent and help in relieving like diabetes, and being a cosmetic field. The aloe plant is need to a greater research emphasis for better utilization of this plant in humankind welfare, it remains for us to introduce to ourselves and thank the nature for its never-ending gift. Furthermore, study all principles of aloe vera needs to be evaluated in future for scientific using, so that its other therapeutic uses can be widely explored. Isolation and maintenance procedures of aloe products are require special care and these have been established after painstaking efforts.

\section{References}

1. GY Yeh, DM Eisenberg, TJ Kaptchuk, RS Phillips (2003) Systematic Review of Herbs and Dietary Supplements for Glycemic Control in Diabetes. Diabetes Care 26 (4): 1277-1294.

2. PRV Santos, ACX Oliveria, TCB Tomassini (1995) Controls Microbiological Products Fitoterapices, Revista de Farmácia e Bioquímica 31: 35-38.

3. RA Mothana, V Linclequist (2005) Antimicrobial Activ-ity of Some Medicinal Plants of the Island Soqotra. Journal of Ethnopharmacology 96(2): 177-181.

4. V E Tyler (1994) Herbs of Choice. Pharmaceutical Products Press, New York, US.

5. Cock IE (2004) Antimicrobial Activity of Aloe barbadensis Miller Leaf Gel Components. The Internet Journal of Microbiology.

6. Alemdar S, Agaoglu S (2009) Investigation of in vitro antimicrobial activity of Aloe vera juice. Journal of animal and veterinary advances 8: 99-102.

7. JP Heggers, A Kucukcelibi, CJ Stabenou, F Ko, LD Broemeling, MC Robson, WD Winters (1995) Wound Healing Effects of Aloe Gel and Other Topical Antibacterial Agents in Rat Skin. Phytotherapy Research 9(6): 455-457.

8. Eberendu Alexis R, L Gabriela, E Joshua A, Mcanalley BH, R Santiago, et al. (2005) Quantitative Colorimetric Analysis of Aloe Polysaccharides as a Measure of Aloe vera Quality in Commercial Products. Journal of AOAC International 8: 684-691.

9. Ferro VA, Bradbury F, Cameron P, Shakir E, Rahman SR, et al. (2003) In vitro susceptibilities of Shigella flexneri and Streptococcus pyogenes to inner gel of Aloe barbadensis Miller. Antimicrobial agents and Chemotherapy 1137-1139.

10. 0 Azghani, I Williams, DB Holiday, AR Johnson (1995) A Beta-Linked Mannan Inhibits Adherence of Pseudomonas aeruginosa to Human Lung Epithelial Cells. Glycobiology 5(1): 39-44.

11. Kaithwas G, Kumar A, Pandey H, Himanshu Pandey, Ajit Kumar Acharya, Mamta Singh, et al. (2008) Investigation of comparative antimicrobial activity of Aloe vera gel and juice. Pharmacologyonline 1: 239-243.

12.00 Agarry, MT Olaleye, CO Bello-Michael (2005) Comparative Antimicrobial Activities of Aloe vera Gel and Leaf. African Journal of Biotechnology 41(2): 1413-1414.

13. Hamman JH (2005) Composition and applications of aloe vera leaf gel. Molecules 13: 1599-1616.

14. L Lorenzetti, R Salisbury, J Beal, J Baldwin (1964) Bacteriostatic Property of Aloe vera. J Pharmacol Sci 53: 1287.

15. K Saoo, H Miki, M Ohmori, WD Winters (1990) Antiviral Activity of Aloe Extracts against Cytomegalovirus. Phytotherapy Research 10(4): 348350.

16. RJ Sydiskis, DG Owen, JL Lohr, KH Rosler, RN Blomster (1991) Inactivation of Enveloped Viruses by Anthraquinones Extracted from Plant. Antimicrobial Agents and Chemotherapy 35(12): 2463-2466.

17. DJ de Rodríguez, D Hernández-Castillo, R Rodríguez- García, JL AnguloSanchez (2005) Antifungal Activity in Vitroof Aloe veraPulp and Liquid Fraction against Plant Pathogenic Fungi. Industrial Crops and Products 21(1): 81-87. 
18. Sumbul S, Ahmed SW, Azhar I (2004) Antifungal activity of Allium, Aloe, and Solanum species. Pharmaceut Biol 42: 491-498.

19. CA Newall, LA Andersonand, JD Phillipson (1996) Herbal Medicines. A Guide for Health-Care Professionals. The Pharmaceutical Press, London.

20. VA Ferro, F Bradbury, P Cameron, E Shakir, SR Rahman, et al. (2003) In Vitro Susceptibilities of Shigella flexneri and Streptococcus pyogenes to Inner Gel of Aloe barbadensis Miller. Antimicrobial Agents and Chemotherapy 47(3): 1137-1139.

21. Peter (2002) Aloe vera Myth or Medicine? Positive Health Publications, Denmark, Europe.

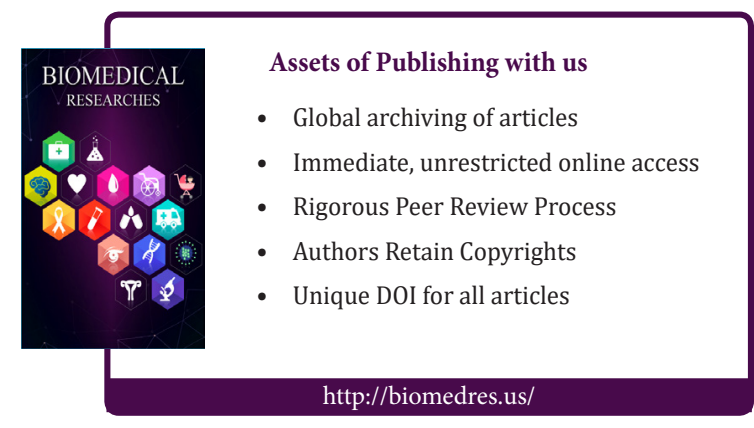

